\title{
Clinical Study \\ Th1/Th2 Cytokine Ratio in Tissue Transudates from Patients with Oral Lichen Planus
}

\author{
Nelson L. Rhodus, ${ }^{1,2}$ Bin Cheng, ${ }^{3}$ and Frank Ondrey ${ }^{2}$ \\ ${ }^{1}$ Division of Oral Medicine and Diagnosis, Department of Diagnostic and Biological Sciences, School of Dentistry, \\ University of Minnesota, Minneapolis, MN 55455, USA \\ ${ }^{2}$ Department of Otolaryngology, School of Medicine, University of Minnesota, Minneapolis, MN 55455, USA \\ ${ }^{3}$ Guanghua School of Stomatology, Sun Yat-Sen University, Guangzhou 510060, China
}

Received 12 September 2006; Revised 17 December 2006; Accepted 17 December 2006

\begin{abstract}
Objective. The characteristics of oral lichen planus (OLP) provoke investigators to explore possible biomarkers by which to monitor disease activity and therapeutic efficacy. Oral fluids may provide an accessible medium for analysis of such biomarkers. Previous studies have shown that activation of nuclear factor-kappa B (NF- $\kappa$ B) plays an important role in the pathogenesis of oral lichen planus (OLP), which is a chronic inflammatory disorder mediated by $\mathrm{T}$ cells. Prior to the present investigation, reports of the levels of NF- $\kappa$ B and its dependent cytokines in oral fluids have not been forthcoming. The purpose of this study was to detect the level of NF- $\kappa$ B dependent cytokines, TNF-alpha, IL-1-alpha, IL-6, and IL-8 in tissue transudates directly from lesions of OLP, and explore the feasibility of the data for clinical application. Study design. Thirteen definitively diagnosed OLP subjects were enrolled in the study as were 13 age-sex matched controls. In each subject, lesion tissue transudates (TTs) were collected by a novel collection technique with a filter paper. The level of cytokines, TNF-alpha, IL-1-alpha, IL-6, and IL-8 in three types of oral fluids were determined by ELISA. Results. In the tissue transudate(TT), there were significantly higher level of cytokines TNF-alpha, IL-1-alpha, IL-6, and IL-8 detected in OLP patients than in controls: (TT: $40.0 \pm 9.8$ versus $4.5 \pm 0.7,710 \pm 114$ versus $305 \pm 78$, $150 \pm 25$ versus $1.7 \pm 0.5,2800 \pm 260$ versus $1450 \pm 130, P<.0001$; unit: pg/mL). Conclusions. These results indicate that NF- $\kappa$ B dependent inflammatory cytokines may be detected at increased levels in oral lesion tissue transudates which may have diagnostic and prognostic potentials for monitoring disease activity and making therapeutic decisions in patients with OLP.
\end{abstract}

Copyright (C) 2007 Nelson L. Rhodus et al. This is an open access article distributed under the Creative Commons Attribution License, which permits unrestricted use, distribution, and reproduction in any medium, provided the original work is properly cited.

\section{INTRODUCTION}

Evidence from investigations using mouse and human models has indicated that $\mathrm{T}$ helper cells can be classified into at least two functional subsets, Th1 and Th2, on the basis of their cytokine profiles. Th1 cells were characterized by the production of IL- 2 , IFN- $\gamma$ and TNF- $\beta$ and were critical in the cell-mediated immunity, but Th2 cells were characterized by the production of IL-4, IL-5, IL-6, and IL-13 and played an important role in humoral immunity. These two Th subsets regulated each other's function through the antagonistic activity of their respective cytokines which determined in large extent the characteristics of immune responses and developments $[1,2]$. Many studies have demonstrated a close relationship between Th1/Th2 imbalance and pathogenesis of a series of autoimmune disorders including Behcet's disease (Th1 dominant response), Sjogren syndrome secondary to hepatitis $\mathrm{C}$ virus infection (Th2 dominant response), psoriasis (Th1 dominant response), and others [3-5]. Increasing evidences showed that the balance of immune responses between Th1 and Th2 determined outcomes of diseases and modulation of Th1/Th2 imbalance became a new therapeutic strategy of some autoimmune diseases, for example, IL-4 in psoriasis, anti-CD4 monoclonal antibody in experimental arthritis, and IFN- $\gamma$ in corticosteroids-resistant asthma [6-8].

Oral Lichen planus (OLP) is a chronic inflammatory disorder characterized by a T-cell-mediated immune response against epithelial cells, with persistent accumulation of $\mathrm{T}$ lymphocytes and epithelial cell damage. Previous studies have described the expression pattern of the different cytokines/chemokines, which involved in Th1 and/or Th2 polarization, in tissues, cultured cells, and serum from patients with OLP, including IL-2 [9-11], IFN-alpha [11-14], TNFalpha $[9,11,12,15-18]$, IL-4 [9, 12, 18], IL-6 [11, 13, 18, 19], IL-10 $[9,12,18]$, and TGF-alpha $[9,12,20]$, IL-1 [18], IL$8[21,22]$. From these results, Sugerman et al. concluded that OLP was characterized by Th1 cytokine bias [23]. This 
conclusion has not been supported by the study on Th1/Th2 cytokine ratio in OLP, one of the direct indicators of Th1/Th2 imbalance.

In this small pilot study, our focus was on the shift of TNF-alpha/IL-6, IL-1/IL-6, and IL-8/IL-6 ratio in tissues transduates (TT) of OLP subjects, one of the diagnostic mediums reflecting exactly local immune response of oral cavity.

\section{MATERIALS AND METHODS}

\subsection{The clinicopathological data of subjects}

All subjects were from the University of Minnesota Oral Medicine Clinic and Hospital of Stomatology, Sun Yat-Sen University. With the approval of the Committee for the Use of Human Subjects in Research, informed consent was obtained from all subjects.

Thirteen patients clinically diagnosed as OLP [24] and 13 age-sex matched healthy individuals were recruited for the study. They had to comply with the following criteria: (1) the absence of any detectable gingival and/or periodontal inflammation and other visible oral lesions, (2) the absence of history of local and systematic diseases, (3) the absence of medication record, for example, anticholinergics, antihistamines, antihypertensives, beta-adrenergic blockers, and other regimen inducing hyposalivation, and (4) the absence of previous or current treatment. Their characteristics were listed in Table 1 .

The biopsy was taken from each patient, following collection of oral fluids, and the tissue specimens were processed by the Department of Oral Pathology at both universities. The pathologic diagnosis confirmed by two oral pathologists independently was consistent with clinical diagnosis.

\subsection{Collection of tissue transudates}

The lesion tissue transudates (TT) were collected by a modified technique [25]. Briefly, the TT was collected after slightly drying the OLP lesion area and then by placing a Periopaper strip directly over the area for 30 seconds. In control group, the TT was collected by the same method on the corresponding anatomic site. The volume of TT was quantified on the Periotron (Harco, Tustin, Calif, USA) and the paper strips were placed in $1.5 \mathrm{~mL}$ micropipette tubes containing $1 \mathrm{~mL}$ of saline solution. After collection, all samples were immediately stored at $-20^{\circ} \mathrm{C}$ until assayed.

\subsection{Detection of cytokines}

Prior to analysis, a sample from the paper strips was eluted by 3 serial centrifuge extractions, each using $1 \mathrm{~mL}$ of PBS buffer solution at $10000 \mathrm{rpm}$ for 30 seconds, and was combined with the saline which the paper strips were initially stored in immediately after collection.

Then all samples were thawed on ice in the lab and were centrifuged at $6000 \mathrm{rpm}$ for 20 minutes. Supernatants were drawn off and used in the ELISA cytokine assays. For Each sample, $100 \mu \mathrm{L}$ supernatant was used for these assays.
TABLE 1: Clinical features of subjects.

\begin{tabular}{lcc}
\hline & OLP $(n=13)$ & Control $(n=13)$ \\
\hline Age $(y)$ & $57 \pm 11$ & $58 \pm 12$ \\
$\quad$ Mean \pm SD & $42 \sim 68$ & $40 \sim 74$ \\
$\quad$ Range & & \\
Gender & $13 / 0$ & $13 / 0$ \\
$\quad$ F/M & & \\
Clinical classification & 9 & - \\
$\quad$ Erosive & 2 & - \\
$\quad$ Reticular and/or plaque-like & 2 & - \\
$\quad$ Atrophic & & - \\
Site & 11 & - \\
$\quad$ Buccal mucosa & \\
$\quad$ Buccal mucosa and gingiva & 2 & - \\
Histological classification & & \\
$\quad$ OLP & 12 & \\
OLP and mild dysplasia & 1 & \\
\hline
\end{tabular}

TNF-alpha, IL-1-alpha IL-6, and IL-8 concentrations were determined by the quantitative sandwich ELISA technique as previously described [26], using commercially available kits (R\&D Systems Inc., Minneapolis, Minn, USA) with a sensitivity of less than $3 \mathrm{pg} / \mathrm{mL}$. Briefly, Costar 96-well EIA Plates were coated with a $1: 1000$ dilution of $1 \mathrm{mg} / \mathrm{mL}$ anti-IgA (Dako). Plates were incubated overnight. Standards, samples, and blanks were incubated for 2 hours. Sample dilutions ranged from $1: 50000$ to $1: 200000$ and standards ranged from 0.5 to $10 \mathrm{ng} / \mathrm{mL}$ (Sigma). Biotinylated antibodies for each cytokine were incubated for 2 hours. Avidin-alkaline phosphatase conjugate (Organon Teknika, The Netherlands) was incubated for 2 hours. Phosphatase substrate was added and was allowed to develop for 30 minutes in the dark and reaction was stopped with $1 \mathrm{~mol} / \mathrm{L}$ $\mathrm{NaOH}$. All incubations were at $37^{\circ} \mathrm{C}$. All plates were washed between each step with PBS-Tween wash buffer. Absorbance was measured at $450 \mathrm{~nm}$ using software from the Molecular Devices Corporation. The standard curves were plotted on a log-log scale. Sample concentrations were determined by linear regression of log average column absorbance against log standard concentration. R-squared values for typical log-log standard curves were $>0.98$; column coefficients of variation ranged between $10 \%-20 \%$. Correlations between sample dilutions were $>0.90$.

\subsection{Statistics}

Data were expressed as mean \pm standard deviation (SD). Since it was not clear whether the data were distributed normally, the test of data normality (Shapiro-Wilk test), Mann-Whitney test, and independent-samples $t$ test were performed, respectively. $P<.05$ was considered to be statistically significant. Statistical Package for Social Studies (SPSS, Version 11.0, SPSS Inc., Chicago, Ill, USA) software was used to analyze the data. 
TABLE 2: The Levels of four cytokines in TT from subjests $(\mathrm{pg} / \mathrm{mL})$.

\begin{tabular}{lcccc}
\hline Group & TNF-alpha & IL-1-alpha & IL-6 & IL-8 \\
\hline OLP $(n=13)$ & $40.0 \pm 9.8$ & $710 \pm 114$ & $150 \pm 25$ & $2800 \pm 260$ \\
C $(n=13)$ & $4.5 \pm 0.7$ & $305 \pm 78$ & $1.7 \pm 0.5$ & $1450 \pm 130$ \\
$t$ value & 13.23 & 10.60 & 21.44 & 16.80 \\
$P$ value & $<.0001$ & $<.0001$ & $<.0001$ & $<.0001$ \\
\hline
\end{tabular}

TABLE 3: Th1/Th2 cytokine ratio in TT.

\begin{tabular}{lccc}
\hline Group & TNF-alpha /IL-6 & IL-1/IL-6 & IL-8/IL-6 \\
\hline OLP $(n=13)$ & $0.3 \pm 0.1$ & $4.8 \pm 0.9$ & $19 \pm 3$ \\
C $(n=13)$ & $3.0 \pm 1.0$ & $200 \pm 78$ & $947 \pm 273$ \\
$t$ value & 9.671 & 9.034 & 12.255 \\
$P$ value & .0001 & .0001 & .0001 \\
\hline
\end{tabular}

\section{RESULTS}

All data were confirmed to be normal distribution by Shapiro-Wilk test. The same results were obtained from both nonparametric and parametric tests. The statistical results of independent-samples $t$ test were presented in Tables 2 and 3.

\section{DISCUSSION}

The Th1/Th2 balance hypothesis emerged in the late 1980s. Currently, much of the literatures have elevated the Th1/Th2 balance concept to the level of paradigm, moreover cytokine and anticytokine therapies, derived from the concept of modulating Th1/Th2 imbalance, have been successfully applied to several autoimmune diseases [27], including Sjogren syndrome [28, 29], psoriasis [6], and corticosteroidsresistant asthma [8]. Yet some observations indicated that addressing the role of individual cytokines during immune response may be far more informative than using the blanket Th1/Th2 descriptors [2]. In OLP, an inflammatory oral mucosal disorder mediated by $\mathrm{T}$ cells, however, several lines of studies on individual cytokines introduced above seem not able to outline the general immune response in OLP and not to give some new insights into the therapy strategy of OLP so that the application of cytokine and anticytokine therapies to OLP seems to have long way to go. Thus, it is necessary to investigate the possible Th1/Th2 pattern in OLP which will be beneficial to its treatment.

Traditionally, IL-2 and IFN- $\gamma$, IL-4 and IL-5 were classified into Th1 cytokine and Th2 cytokines, respectively. As more and more cytokines have been described and characterized, some cytokines that were not necessarily secreted by $\mathrm{CD}^{+} \mathrm{T}$ cells promoted the development of either Th1 or Th2 cells [2]. For example, TNF-alpha, IL-1, and IL-8 as Th1associated cytokines and IL- 6 as Th2-associated cytokines have been assigned in some investigations $[30,31]$. In this preliminary study, TNF-alpha, IL-1, IL-8, and IL-6 were assigned to Th1 and Th2 cytokines, respectively. The level of TNF-alpha, IL-1-alpha, IL-6 and IL-8 in TT of OLP patients and normal controls was determined. Our results showed that the concentration of TNF-alpha, IL-1-alpha, IL-6, and
IL-8 was significantly higher in TT of OLP patients than in that of controls, furthermore all ratios of cytokines, TNFalpha/IL-6, IL-1/IL-6, and IL-8/IL-6 in OLP patients were decreased significantly, compared with that of controls. This result is, to our knowledge, the first to suggest the presence of a Th2 cytokine-dominant condition in these limited subjects of OLP. Since previous studies indicated Th1 cytokine bias in OLP [23], it seems to be necessary to evaluate carefully the published data before a conclusion will be made.

In the past analysis on simultaneous expression of Th1 and Th2 cytokines, Simark-Mattsson et al. noted that cells expressing mRNA for IL-2, IL-4, IL-10, TNF- $\alpha$, and TGFbeta 1 were found in all the biopsies studied, and message for IFN- $\gamma$ and IL-10 was detected in the cultured T-cell lines of all the patients [9]. Fayyazi et al. revealed the coexpression of IFN- $\gamma$ and IL-6 mRNA in the upper subepithelial connective tissue and basal and suprabasal keratinocytes of altered skin/oral mucosa [13]. Khan et al. reported that unstimulated OLP lesional T cells secreted IFN- $\gamma$ in vitro but IL-4, IL-10, and TGF-beta 1 secretion were not detected [12]. Yamamoto et al. detected increase of IL-4 and TNFalpha in serum from about one third of the patients, and IL- 6 in all patients $[11,32]$, and they also found that more IFN-alpha, IL-6, and TNF-alpha were generated by tissueinfiltrating mononuclear cells (TIMCs) of OLP, compared to TIMC from the chronically inflamed gingivae [17]. But these studies had not calculated and compared the Th1/Th2 cytokine ratio, the direct evidence of Th1/Th2 balance, in OLP.

Similarly, our detection also showed the simultaneous argumentation of TNF-alpha, IL-1-alpha, IL-8, and IL-6 in TT of OLP patients. However, the decreased ratio of cytokines, TNF-alpha/IL-6, IL-1/IL-6, and IL-8/IL-6, was measured in OLP patients. It may be attributed to the reason that the increase of IL- 6 was far more extent than that of TNF-alpha, IL-1-alpha, IL-8 as seen in Table 2. This result indicated the possibility that a Th2-dominated immune response does occur in a subgroup of OLP patients. Moreover, TT was selected as an analytic medium in our study. With the advantages of safety, minimal invasion, and easy access, several types of body fluids have been applied to a lot of cytokines analyses in clinical and experimental studies, including bronchoalveolar lavage [33, 34], urine [35], synovial fluid [36, 37], and saliva $[38,39]$. Since a series of cytokines produced in tissues of OLP through autocrine and paracrine processes plays important roles in the local inflammatory response of OLP [23], the collection and analysis of TT will avoid the interference of subclinical inflammatory lesions of oral-facial region. The results from TT analysis may more exactly reflect the local immune situation of OLP lesion than that from whole saliva, gingival crevicular fluid, and other oral fluids. Therefore, our findings presented here did give the evidence that a Th2 cytokine-dominanted immune response exists in some cases with OLP.

In summary, our study, together with the previous reports, indicated that the different patterns of Th1/Th2 imbalance, Th1 or Th2 overactivation or mixed Th1/Th2 conditions, may occur in the pathogenesis of OLP. The large scale of patients and more types of cytokines should be included in 
the future researches before the available results will be used in monitoring disease activity and direction of OLP therapy.

\section{ACKNOWLEDGMENTS}

This work was supported in part by the National Natural Scientific Foundation of China to the second author (30371539), and the Division of Oral Medicine, University of Minnesota to the first author (6143901). We thank Dr. Xuan Wang and Xiaobing Chen from Guanghua School of Stomatology, Sun Yat-Sen University, China, for their statistical analysis.

\section{REFERENCES}

[1] J. Rengarajan, S. J. Szabo, and L. H. Glimcher, "Transcriptional regulation of Th1/Th2 polarization," Immunology Today, vol. 21, no. 10, pp. 479-483, 2000.

[2] D. O. Gor, N. R. Rose, and N. S. Greenspan, " $\mathrm{T}_{\mathrm{H}} 1-\mathrm{T}_{\mathrm{H}} 2$ : a procrustean paradigm," Nature Immunology, vol. 4, no. 6, pp. 503-505, 2003.

[3] K. Hamzaoui, A. Hamzaoui, F. Guemira, M. Bessioud, M. Hamza, and K. Ayed, "Cytokine profile in Behçet's disease patients: relationship with disease activity," Scandinavian Journal of Rheumatology, vol. 31, no. 4, pp. 205-210, 2002.

[4] M. Ramos-Casals, M. García-Carrasco, R. Cervera, et al., "Th1/Th2 cytokine imbalance in patients with Sjögren syndrome secondary to hepatitis C virus infection," Seminars in Arthritis and Rheumatism, vol. 32, no. 1, pp. 56-63, 2002.

[5] K. Ghoreschi, U. Mrowietz, and M. Röcken, "A molecule solves psoriasis? Systemic therapies for psoriasis inducing interleukin 4 and Th2 responses," Journal of Molecular Medicine, vol. 81, no. 8, pp. 471-480, 2003.

[6] K. Ghoreschi, P. Thomas, S. Breit, et al., "Interleukin-4 therapy of psoriasis induces Th2 responses and improves human autoimmune disease," Nature Medicine, vol. 9, no. 1, pp. 4046, 2003.

[7] D. Pohlers, K. Nissler, O. Frey, et al., "Anti-CD4 monoclonal antibody treatment in acute and early chronic antigeninduced arthritis: influence on T helper cell activation," Clinical and Experimental Immunology, vol. 135, no. 3, pp. 409-415, 2004.

[8] H.-U. Simon, H. Seelbach, R. Ehmann, and M. Schmitz, "Clinical and immunological effects of low-dose IFN- $\alpha$ treatment in patients with corticosteroid-resistant asthma," Allergy, vol. 58, no. 12, pp. 1250-1255, 2003.

[9] C. Simark-Mattsson, G. Bergenholtz, M. Jontell, et al., "Distribution of interleukin-2, $-4,-10$, tumour necrosis factor- $\alpha$ and transforming growth factor- $\beta$ mRNAs in oral lichen planus," Archives of Oral Biology, vol. 44, no. 6, pp. 499-507, 1999.

[10] F. Chiappelli, M. A. Kung, P. Nguyen, P. Villanueva, E. A. Farhadian, and L. R. Eversole, "Cellular immune correlates of clinical severity in oral lichen planus: preliminary association with mood states," Oral Diseases, vol. 3, no. 2, pp. 64-70, 1997.

[11] E. E. Karagouni, E. N. Dotsika, and A. Sklavounou, "Alteration in peripheral blood mononuclear cell function and serum cytokines in oral lichen planus," Journal of Oral Pathology and Medicine, vol. 23, no. 1, pp. 28-35, 1994.

[12] A. Khan, C. S. Farah, N. W. Savage, L. J. Walsh, D. J. Harbrow, and P. B. Sugerman, "Th1 cytokines in oral lichen planus,"
Journal of Oral Pathology and Medicine, vol. 32, no. 2, pp. 7783, 2003.

[13] A. Fayyazi, S. Schweyer, A. Soruri, et al., "T lymphocytes and altered keratinocytes express interferon- $\gamma$ and interleukin 6 in lichen planus," Archives of Dermatological Research, vol. 291, no. 9, pp. 485-490, 1999.

[14] C. Simark-Mattsson, M. Jontell, G. Bergenholtz, M. Heyden, and U. I. Dahlgren, "Distribution of interferon- $\gamma$ mRNApositive cells in oral lichen planus lesions," Journal of Oral Pathology and Medicine, vol. 27, no. 10, pp. 483-488, 1998.

[15] S. Pezelj-Ribaric, I. B. Prso, M. Abram, I. Glazar, G. Brumini, and M. Simunovic-Soskic, "Salivary levels of tumor necrosis factor- $\alpha$ in oral lichen planus," Mediators of Inflammation, vol. 13, no. 2, pp. 131-133, 2004.

[16] A. Sklavounou, E. Chrysomali, A. Scorilas, and A. Karameris, "TNF- $\alpha$ expression and apoptosis-regulating proteins in oral lichen planus: a comparative immunohistochemical evaluation," Journal of Oral Pathology and Medicine, vol. 29, no. 8, pp. 370-375, 2000.

[17] T. Yamamoto, T. Osaki, K. Yoneda, and E. Ueta, "Cytokine production by keratinocytes and mononuclear infiltrates in oral lichen planus," Journal of Oral Pathology and Medicine, vol. 23, no. 7, pp. 309-315, 1994.

[18] T. Yamamoto and T. Osaki, "Characteristic cytokines generated by keratinocytes and mononuclear infiltrates in oral lichen planus," Journal of Investigative Dermatology, vol. 104, no. 5, pp. 784-788, 1995.

[19] A. Sun, J.-S. Chia, Y.-F. Chang, and C.-P. Chiang, "Serum interleukin-6 level is a useful marker in evaluating therapeutic effects of levamisole and Chinese medicinal herbs on patients with oral lichen planus," Journal of Oral Pathology and Medicine, vol. 31, no. 4, pp. 196-203, 2002.

[20] A. Karatsaidis, O. Schreurs, T. Axéll, K. Helgeland, and K. Schenck, "Inhibition of the transforming growth factor$\beta /$ Smad signaling pathway in the epithelium of oral lichen," Journal of Investigative Dermatology, vol. 121, no. 6, pp. 12831290, 2003.

[21] M. Zehnder, J. S. Greenspan, D. Greenspan, and M. Bickel, "Chemokine gene expression in human oral mucosa," European Journal of Oral Sciences, vol. 107, no. 4, pp. 231-235, 1999.

[22] M. C. Little, C. E. M. Griffiths, R. E. B. Watson, M. N. Pemberton, and M. H. Thornhill, "Oral mucosal keratinocytes express RANTES and ICAM-1, but not interleukin-8, in oral lichen planus and oral lichenoid reactions induced by amalgam fillings," Clinical and Experimental Dermatology, vol. 28, no. 1, pp. 64-69, 2003.

[23] P. B. Sugerman, N. W. Savage, L. J. Walsh, et al., "The pathogenesis of oral lichen planus," Critical Reviews in Oral Biology and Medicine, vol. 13, no. 4, pp. 350-365, 2002.

[24] J. W. Little, D. A. Falace, C. S. Miller, and N. L. Rhodus, Eds., Dental Management of the Medically Compromised Patient, Mosby, Saint Louis, Mo, USA, 6th edition, 2002.

[25] N. L. Rhodus, L. Dahmer, K. Lindemann, J. Rudney, A. Mathur, and J. Bereuter, "s-IgA and cytokine levels in whole saliva of Sjögren's syndrome patients before and after oral pilocarpine hydrochloride administration: a pilot study," Clinical Oral Investigations, vol. 2, no. 4, pp. 191-196, 1998.

[26] F. Ondrey, G. Dong, J. Sunwoo, et al., "Constitutive activation of transcription factors NF- $\kappa \mathrm{B}, \mathrm{AP}-1$, and NF-IL6 in human head and neck squamous cell carcinoma cell lines that express pro-inflammatory and pro-angiogenic cytokines," Molecular Carcinogenesis, vol. 26, no. 2, pp. 119-129, 1999. 
[27] I. Krause, G. Valesini, R. Scrivo, and Y. Shoenfeld, "Autoimmune aspects of cytokine and anticytokine therapies," American Journal of Medicine, vol. 115, no. 5, pp. 390-397, 2003.

[28] M. Voulgarelis, S. Giannouli, D. Anagnostou, and A. G. Tzioufas, "Combined therapy with rituximab plus cyclophosphamide/doxorubicin/vincristine/prednisone (CHOP) for Sjögren's syndrome-associated B-cell aggressive nonHodgkin's lymphomas," Rheumatology, vol. 43, no. 8, pp. 1050-1053, 2004.

[29] M. M. Zandbelt, P. C. M. de Wilde, P. A. van Damme, C. B. Hoyng, L. B. A. van de Putte, and F. H. J. van den Hoogen, "Etanercept in the treatment of patients with primary Sjögren's syndrome: a pilot study," Journal of Rheumatology, vol. 31, no. 1, pp. 96-101, 2004.

[30] S. Diehl and M. Rincón, "The two faces of IL-6 on Th1/Th2 differentiation," Molecular Immunology, vol. 39, no. 9, pp. 531-536, 2002.

[31] S. Babu and T. B. Nutman, "Proinflammatory cytokines dominate the early immune response to filarial parasites," Journal of Immunology, vol. 171, no. 12, pp. 6723-6732, 2003.

[32] T. Yamamoto, K. Yoneda, E. Ueta, and T. Osaki, "Serum cytokines, interleukin-2 receptor, and soluble intercellular adhesion molecule-1 in oral disorders," Oral Surgery, Oral Medicine, Oral Pathology, vol. 78, no. 6, pp. 727-735, 1994.

[33] U. Costabel and J. Guzman, "Bronchoalveolar lavage in interstitial lung disease," Current Opinion in Pulmonary Medicine, vol. 7, no. 5, pp. 255-261, 2001.

[34] L. Liu, N. N. Jarjour, W. W. Busse, and E. A. B. Kelly, "Enhanced generation of helper $\mathrm{T}$ type 1 and 2 chemokines in allergen-induced asthma," American Journal of Respiratory and Critical Care Medicine, vol. 169, no. 10, pp. 1118-1124, 2004.

[35] F. Saint, N. Kurth, P. Maille, et al., "Urinary IL-2 assay for monitoring intravesical bacillus Calmette-Guérin response of superficial bladder cancer during induction course and maintenance therapy," International Journal of Cancer, vol. 107, no. 3, pp. 434-440, 2003.

[36] S.-H. Park, D.-J. Min, M.-L. Cho, et al., "Shift toward T helper 1 cytokines by type II collagen-reactive T cells in patients with rheumatoid arthritis," Arthritis and Rheumatism, vol. 44, no. 3, pp. 561-569, 2001.

[37] K. Kaneyama, N. Segami, J. Sato, M. Nishimura, and H. Yoshimura, "Interleukin-6 family of cytokines as biochemical markers of osseous changes in the temporomandibular joint disorders," British Journal of Oral and Maxillofacial Surgery, vol. 42, no. 3, pp. 246-250, 2004.

[38] P. Sfriso, P. A. Ostuni, C. Botsios, et al., "Serum and salivary neopterin and interferon- $\gamma$ in primary Sjögren's syndrome: correlation with clinical, laboratory and histopathologic features," Scandinavian Journal of Rheumatology, vol. 32, no. 2, pp. 74-78, 2003.

[39] S. Ruhl, S. Homberaer, R. Betz, et al., "Salivary proteins and cytokines in drug-induced gingival overgrowth," Journal of Dental Research, vol. 83, no. 4, pp. 322-326, 2004. 


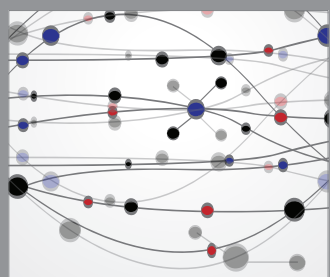

The Scientific World Journal
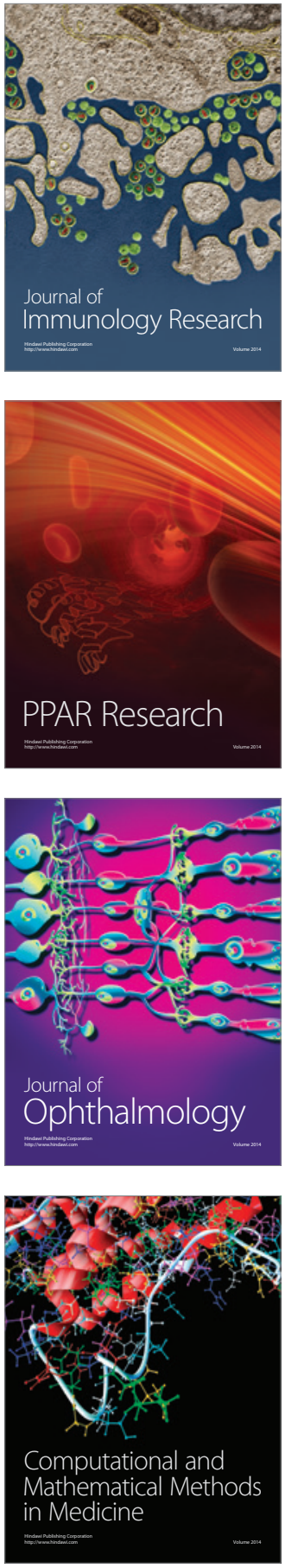

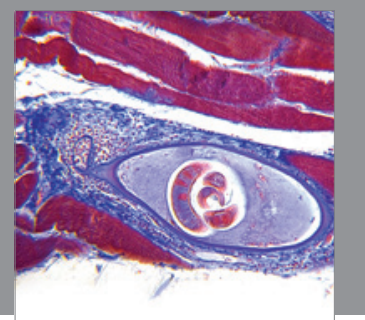

Gastroenterology

Research and Practice
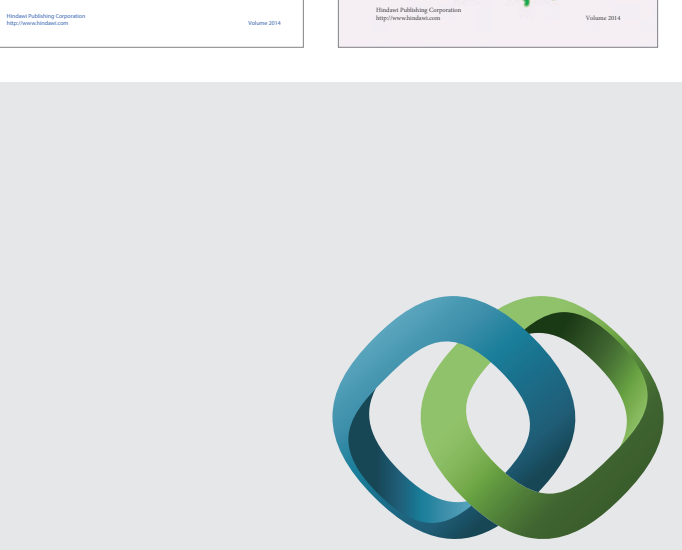

\section{Hindawi}

Submit your manuscripts at

http://www.hindawi.com
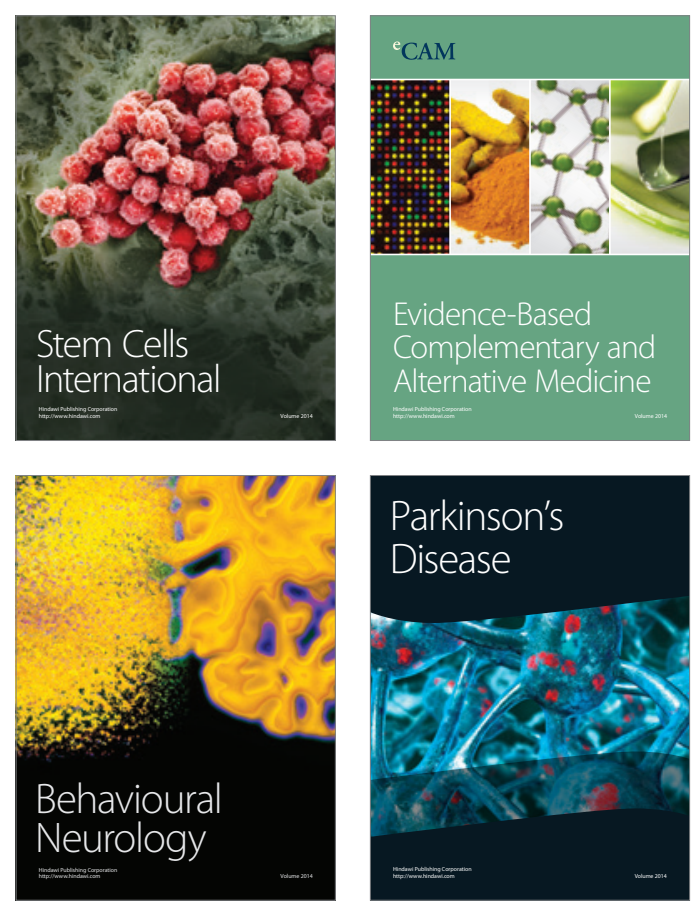

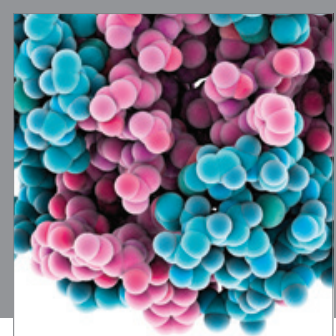

Journal of
Diabetes Research

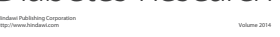

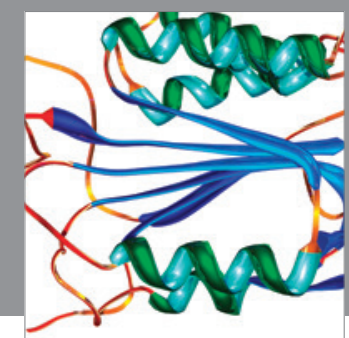

Disease Markers
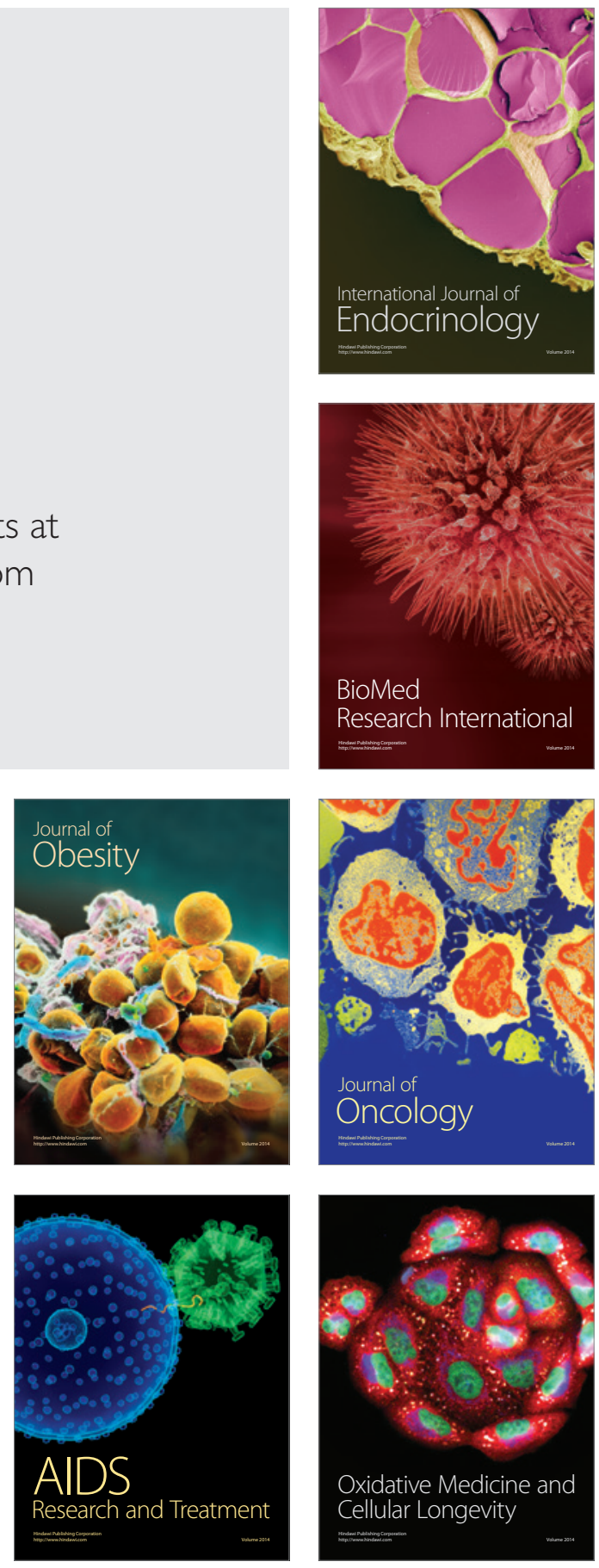